\title{
The effect of pre-slaughter stress resulting from feed withdrawal on meat quality characteristics in ostriches
}

\author{
S.J. van Schalkwyk ${ }^{1}$, S.W.P. Cloete ${ }^{2}$, L.C. Hoffman ${ }^{3}$, Z. Brand ${ }^{1}$, A.P. Pfister ${ }^{1}$ and K. Punt $^{1}$ \\ ${ }^{1}$ Klein Karoo Agricultural Development Centre, PO Box 351, Oudtshoorn, 6620 \\ ${ }^{2}$ Elsenburg Agricultural Development Centre, Private Bag X1, Elsenburg, 7607 \\ ${ }^{3}$ Dept of Animal Science, University of Stellenbosch, Private Bag X5018, Stellenbosch, 7599 \\ Email :Kootvs@wcape.agric.za
}

\section{Introduction}

Ostriches in SA are slaughtered for meat and leather production between 9 and 4 months of age. Slaughter birds are usually kept for 12-24 hours prior to slaughter in small holding pens with access to water only. Birds delivered on Fridays to be slaughtered on Mondays have access to feed as well. Sales (1994) and Sales and Mellett (1996) suggested that pre-slaughter stress factors include transportation, handling and feed deprivation. Observations by abattoir staff suggested that slaughter birds consumed very little (if any) of the feed provided during the weekend. Relationships between postmortem findings and ante-mortem handling in ostriches are not clear because of insufficient research on this topic. The aim of this study was to investigate the effect of feed deprivation on meat quality by simulating conditions typical of those birds slaughtered on Mondays.

\section{Material and Methods}

Eighty four slaughter ostriches drawn at random from the commercial ostrich breeding flock maintained on the Klein Karoo Agricultural Development Centre near Oudshoorn were slaughtered at the commercial ostrich abattoir at Oudtshoorn during August-September 1999. The average age of the experimental animals at slaughter was $275( \pm 42)$ days, and the animals were stratified to represent a fairly wide range of live weights from 50 to 100 $\mathrm{kg}$. Approximately half of these animals (38) had food withheld from them for a period of 2-3 days prior to slaughter in order to simulate the effect of stress experienced by animals delivered to the abattoir for slaughter and held in the holding pens over a weekend. The remainder of the birds were treated as controls and received the same commercial diet ad libitum. All animals had unrestricted access to clean drinking water. All animals were weighed prior to the period of food restriction as well as prior to transportation to the abattoir. Drumstick weights were recorded immediately after slaughter and after a 24-hour refrigeration period. Temperature and $\mathrm{pH}$ recordings were made within the right fillet (M.iliofibrularis) immediately post slaughter, and again after time lapses of 1.5, 4.5, $9.25,12.75$ and 24 hours respectively. Fillet muscles (M. iliofibrularis) were dissected from the left drumsticks of 47 individual carcasses. Representative samples (approximately 50-100 g) of the muscles were taken and used for the determination of cooking loss, drip loss and shearing strength. Sex was recorded for each individual bird. The data were analyzed as a 2 (treatments) X 2 (sex: male or female) factorial, employing least squares procedures to account for uneven subclasses (Harvey, 1990).

\section{Results and Discussion}

Slaughter age, initial live weight and drumstick weight were independent $(P \geq 0.20)$ of treatment, sex and their interaction. The mean weight loss of stressed birds during the experimental period was approximately three times that of control birds ( $3.23 \pm 0.56$ vs. $1.04 \pm 0.51 \mathrm{~kg} ; \mathrm{P}<0.01)$. Sales (1994) reported live weight losses of 10 $17 \%$ during holding prior to slaughter. Full stomach alimentary tract weight did not differ between treatments. Ostrich meat is usually classified as an intermediate meat type due to a high $\mathrm{pH}$ after cooling for 24 hours, which is situated between normal $\mathrm{pH}(\mathrm{pH}<5.8)$ and that of extremely dark, firm dry meat ( $\mathrm{pH}>6.2)$ (Lambooij, 1999). The intra-muscular $\mathrm{pH}$ of stressed birds was $3.7 \%$ higher $(\mathrm{P}<0.01)$ than that of contemporaries in the control group immediately post slaughter (Table 1). After 26.5 hours in a refrigerated room, this difference still remained at $4.0 \%(\mathrm{P}<0.05)$. Post slaughter changes in intra-muscular $\mathrm{pH}$ followed approximately the same trend in stressed and control birds. In contrast to our results, which indicated an increase in $\mathrm{pH}$ towards 24 hours postslaughter, Sales (1994) and Sales and Mellett (1996) suggested a rapid drop in pH 2 hours after slaughter for all muscle groups. However, Mellett (1985) and Sales (1994) reported a steady subsequent increase in $\mathrm{pH}$ for the $M$. iliofibrularis after the initial drop in $\mathrm{pH}$. Intra-muscular temperature was largely independent of treatment, although there was a suggestion of a slightly higher $(\mathrm{P}=0.18)$ temperature in stressed birds immediately post 
Short paper and poster abstracts: $38^{\text {th }}$ Congress of the South African Society of Animal Science

slaughter. Cooking loss, drip loss and shearing values was not affected $(\mathrm{P}>0.20)$ by the withholding of food for 23 days (Table 1 ).

Table 1 Means (SE) for meat quality parameters of ostrich M. Iliofibrularis in relation to stress treatment (withdrawal of food for 2-3 days or untreated control)

\begin{tabular}{lccc}
\hline Trait & Control & Treatment & Significance \\
& & & \\
\hline Number of observations & 25 & 22 & \\
pH: & & $6.03(0.06)$ & $* *$ \\
Directly post slaughter & $5.81(0.05)$ & $6.46(0.07)$ & $*$ \\
26.5 hrs post slaughter & $6.21(0.07)$ & $39.84(0.47)$ & 0.18 \\
Temperature $\left({ }^{\circ} \mathrm{C}\right)$ : & $38.95(0.44)$ & $2.13(0.08)$ & $\mathrm{ns}$ \\
Directly post slaughter & $2.19(0.07)$ & $29.1(1.3)$ & $\mathrm{ns}$ \\
26.5 hrs post slaughter & $30.8(1.2)$ & $1.88(0.26)$ & $\mathrm{ns}$ \\
& $2.18(0.24)$ & $0.067(0.007)$ & $\mathrm{ns}$ \\
Cooking loss $(\%)$ & $0.078(0.006)$ & & \\
Drip loss $(\%)$ & &
\end{tabular}

\section{Conclusion}

The high $\mathrm{pH}$ after being refrigerated for 24 hours, particularly in the stressed group, indicated a dark, firm dry meat which is not acceptable for consumers. Shelf life may also be influenced due to microbial spoilage as a result of the high $\mathrm{pH}$. Further research is required to get a better indication of the influence of various manifestations of stress on ostrich meat quality.

\section{References}

Harvey, W.R., 1990. Users guide for LSMMLMW and MIXMDLPG2 version Mimeograph.

Lambooij, E., 1999. Research Proposal; the ostrich as a slaughter bird. pp 5-7.

Mellett, F.D., 1985. Ph.D. thesis, University of Stellenbosch.

Sales, J. \& Mellett, F.D., 1996. Meat Sci. 42, 235.

Sales, J., 1994. Ph.D. thesis, University of Stellenbosch. 